switch is higher than a historical cohort of etanercept reference drug. This is expected, since it is a selected group of etanercept responders. The interpretation of the results should be cautious, since only few patients are included in this first analysis. A larger number of patients from other participating out-patient clinics is planned to be included.

Disclosure of Interests: Glenn Haugeberg Grant/research support from: For this study grant from Biogen, Consultant for: Medical Advisory boards for several companies, Paid instructor for: I have been paid for giving lectures for pharmaceutical companies and their employees, Speakers bureau: I have been paid for giving lectures in meetings organized by pharmaceutical companies, Bjørg Tilde Svanes Fevang: None declared, Gunnstein Bakland: None declared, Erik Rødevand: None declared, Andreas Diamantopoulos: None declared

DOI: 10.1136/annrheumdis-2019-eular.7423

\section{SAT0147 EFFECTS OF BIOLOGICAL DISEASE-MODIFYING ANTI- RHEUMATIC DRUG TREATMENT ON PHYSICAL ACTIVITY, MUSCLE POWER, AGILITY AND INHIBITION OF FALL IN PATIENTS WITH RHEUMATOID ARTHRITIS}

Yuji Hirano $^{1}$, Ayako Morisaka ${ }^{2}$, Daisuke Kihira ${ }^{1}$, Shiori Inuzuka ${ }^{2}$, Takeshi Kamiya ${ }^{2}$, Hiroyuki Mori ${ }^{2}$, Naohito Morishima ${ }^{2}$, Tomoji Ishikawa ${ }^{3} .{ }^{1}$ Toyohashi Municipal Hospital, Rheumatology, Toyohashi, Japan; ${ }^{2}$ Toyohashi Municipal Hospital, Rehabilitation Center, Toyohashi, Japan; ${ }^{3}$ Toyohashi Municipal Hospital, Rehabilitation Medicine, Toyohashi, Japan

Background: It has been demonstrated that biological DMARDs (bDMARDs) treatment rapidly improved sign and symptom in patients with rheumatoid arthritis (RA). Those were evaluated using composite measures or biomarkers in daily clinical practice or clinical studies. Although rapid improvement of composite measures or biomarkers is important in the treatment of RA, primary important goal of treatment is improvement of long term health-related quality of life (HR-QOL) [1]. HR-QOL is based on physical function such as muscle power and agility.

Objectives: This study investigated the efficacy of bDMARDs on physical function and fall risk in patients with RA.

Methods: Periodic evaluation of physical function by the staffs in rehabilitation center in our institute has been performed in addition to routine rheumatology evaluation (SDAl, biomarkers, $\mathrm{mHAQ}$ ) in RA patient initiated their first bDMARDs treatment from Oct. 2015 to Feb. 2018. 47 cases was registered in total. Evaluation of physical function included evaluation of muscle power (grasping power [GP] and knee extension power [KEP]), agility (Time up and go test [TUG] and $10 \mathrm{~m}$ walking time $[10 \mathrm{~mW}]$ ) and questionnaire using $\mathrm{mHAQ}$, portable fall risk index [2] and the 25-question geriatric locomotive function scale (locomo25) [3] at baseline (initiation of bDMARDs), 1month, 3months, 6months and 12months. Disease activity of RA (SDAI, CRPMMP-3) was evaluated at same time point. Although 26 cases have passed one year from initiation of bDMARDs treatment, 9 cases dropped out from evaluation of physical function due to stopping of bDMARDs treatment or patient's hope not to e evaluated on physical function or major joint surgery performed in patient which was influence physical function. Results of early 17 cases who completed evaluation at 12 months were investigated in this study.

Results: Baseline patients characteristics was as follow $(n=17)$ : mean age 59.1 years old, RA duration 13.7 years, Mean SDAI 19.6, mean CRP $1.9 \mathrm{mg} / \mathrm{dl}$. Used bDMARDs were tocilizumab in 5 cases, golimumab in 4 cases, etanercept in 3 cases, abatacept in 3 case, certolizumab in one case and infliximab-biosimilar in one case. Date is presents as mean values at baseline-1-3-6-12 months below. SDAI and CRP were significantly improved on and after one month (SDAl: 19.6-9.6-5.8-5.7-5.5, CRP [mg/ dl]: $1.9-0.3-0.3-0.3-0.8)$. GP and knee extension power significantly improved on and after one months except KEP at 3 months (GP [kg]: 12.3-14.1-15.9-16.9-17.4, KEP [N/kg] 2.6-3.1-3.1-3.4-3.5). TUG at $10 \mathrm{~mW}$ significantly improved on and after one months except TUC at 3months and $10 \mathrm{~mW}$ at 3 months (TUG [s]: 9.3-8.0-8.2-7.3-7.4, 10mW[s]: 8.3-7.77.5-6.9-6.8). MHAQ significantly improved on and from 6 months (0.460.33-0.19-0.20-0.12). Locomo25 significantly improved on and from 1 month (31.7-20.6-18.5-16.7-15.0). Portable fall risk index significantly improved at only 12 months (8.8-8.6-7.8-7.8-6.8).
Fig1. Mean values and p-value by bDMARDs Treatment in RA Patients

\begin{tabular}{|l|c|c|c|c|c|}
\hline & Baseline & 1 month & 3 months & 6months & 12months \\
\hline SDAI & 19.6 (Cont.) & $9.6(<0.01)$ & $5.8(<0.01)$ & $5.7(<0.01)$ & $5.5(<0.01)$ \\
\hline CRP (mg/dl) & 1.9 (Cont.) & $0.3(<0.01)$ & $0.3(<0.01)$ & $0.3(<0.01)$ & $0.8(<0.01)$ \\
\hline Grasping Power (kg) & 12.3 (Cont.) & $14.1(0.049)$ & $15.9(0.01)$ & $16.9(<0.01)$ & $17.4(<0.01)$ \\
\hline KEP (N/kg) & 2.6 (Cont.) & $3.1(0.02)$ & $3.1(0.21)$ & $3.4(<0.01)$ & $3.5(<0.01)$ \\
\hline TUG (second) & 9.3 (Cont.) & $8.0(0.03)$ & $8.2(0.055)$ & $7.3(0.01)$ & $7.4(0.02)$ \\
\hline $10 \mathrm{~mW} \mathrm{(second)}$ & 8.3 (Cont.) & $7.7(0.02)$ & $7.5(0.14)$ & $6.9(<0.01)$ & $6.8(<0.01)$ \\
\hline mHAQ & 0.46 (Cont.) & $0.33(0.12)$ & $0.19(0.02)$ & $0.20(<0.01)$ & $0.13(<0.01)$ \\
\hline locomo25 & 31.7 (Cont.) & $20.6(0.03)$ & $18.5(<0.01)$ & $16.7(<0.01)$ & $15.0(<0.01)$ \\
\hline Fall risk index & 8.8 (Cont.) & $8.6(0.83)$ & $7.8(0.16)$ & $7.8(0.12)$ & $6.8(<0.01)$ \\
\hline
\end{tabular}

Data is expressed as mean (p-value). P-value was caluculated using Wilcoxon signed-rank test between baseline and each month.

SDAI: simplified disease activity index, KEP: knee extention power, TUG: timed up and go test,

$10 \mathrm{~mW}$ : $10 \mathrm{~m}$ walking time, mHAQ: modified health assessment questionnaire

Conclusion: Signs and symptoms of RA were rapidly improved after the initiation of bDMARDs treatment and improvement of physical function was also rapidly improved. The changes from baseline and one month were more drastic in composite measure or biomarker of inflammation than that in muscle power and agility in respect with p-values. Inhibition of fall were achieved 12 months after bDMARDs initiation. These results suggested that physiotherapy might play an important role in RA patients treated with bDMARDs to gain more rapid improvement of physical function.

\section{REFERENCES}

[1] Smolen JS, et al. Ann Rheum Dis 2016.

[2] Toba K, et al. Jpn J Geriat 2005.

[3] Seichi A at al. J Orthop Sci 2012.

Disclosure of Interests: None declared DOI: 10.1136/annrheumdis-2019-eular.2915

\section{SAT0148 IMMUNOGLOBULIN A LEVELS IN ADDITION TO RHEUMATOID FACTOR PREDICTS REMISSION ACHIEVEMENT WITH ABATACEPT IN PATIENTS WITH EARLY RHEUMATOID ARTHRITIS}

Jun Inamo, Yuko Kaneko, Jun Kikuchi, Tsutomu Takeuchi. Keio University School of Medicine, Division of Rheumatology, Department of Internal Medicine, Tokyo, Japan

Background: Biological disease modifying antirheumatic drugs (bDMARDs) now play an important role of clinical practice for patients with rheumatoid arthritis (RA). Abatacept (ABT) has a biologic agent that has an unique mechanism of action suppressing $T$ lymphocyte activation Although many prediction studies about therapeutic responses to bDMARDs for RA have been conducted to date [1], few studies has focused on ABT.

Objectives: The aim of this study was to identify predictive clinical biomarkers for remission achievement with $A B T$ in RA patients.

Methods: We retrospectively reviewed consecutive patients with RA who started ABT from 2010 through 2018 in Keio University Hospital. We defined early $A B T$ use as the initiation of $A B T$ within two years from diagnosis without radiographic progression in hand $X$ rays, and stratified the patients into the early $A B T$ users and the late $A B T$ users. Baseline characteristics were compared between patients who achieved CDAl remission achievement at 6 months and those who did not in both groups.

Results: One hundred and seven RA patients who were treated with ABT with baseline information available were enrolled in the study. Among them, 15 patients were classified into the early ABT users and 92 were the late $A B T$ users, and the remission rates at 6 months were $40 \%$ and $24 \%$, respectively. In the early ABT users, patients who achieved CDAl remission at 6 months showed significantly higher $\lg \mathrm{A} \operatorname{lev}$ els than those who did not achieve remission $(390 \mathrm{mg} / \mathrm{dL}$ vs $279 \mathrm{mg} / \mathrm{dL}$, $\mathrm{P}=0.04$, respectively). The difference in $\lg \mathrm{A}$ disappeared in the late $A B T$ users (332 mg/dL vs $313 \mathrm{mg} / \mathrm{dL}, P=0.60$, respectively). Principal component analysis revealed that in the early $A B T$ users, patients who 
achieved remission and those who did not could be clearly separated by the levels of $\lg A$, $\lg G$, rheumatoid factor, and albumin (Figure), whereas those baseline characteristics were mostly overlapped in the late ABT users (cut-off value for predicting remission with sensitivity and specificity in the early ABT users; IgA $342 \mathrm{mg} / \mathrm{dL}$ with $83 \%$ and $100 \%$, IgG 1880 $\mathrm{mg} / \mathrm{dL}$ with $50 \%$ and $100 \%$, rheumatoid factor $152 \mathrm{IU} / \mathrm{mL}$ with $50 \%$ and $100 \%$, albumin $3.7 \mathrm{~g} / \mathrm{dL}$ with $88 \%$ and $67 \%$, respectively). The area under the curves of receiver operating characteristic curves to predict remission were 0.833 of $\lg A$ and 0.778 of rheumatoid factor titer.

Conclusion: We identified serum IgA titer was the novel predictive factor for response of $\mathrm{ABT}$.

\section{REFERENCE}

[1] Wijbrandts CA, Tak PP. Prediction of Response to Targeted Treatment in Rheumatoid Arthritis. Mayo Clin Proc. 2017;92:1129-1143.

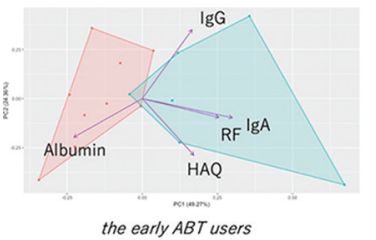

- CDAl remission - non-remission

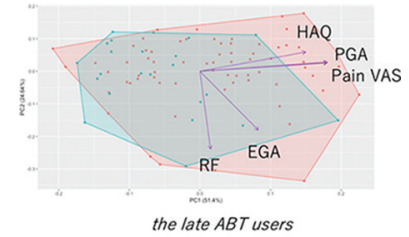

the late $A B T$ users
Figure. Principal component analysis by clinical parameters.RF; rheumatoid factor, $\mathrm{HAQ}$; health assessment questionnaire, EGA; evaluator's global disease activity, PGA; patient global assessment, VAS; visual analog scale

Disclosure of Interests: Jun Inamo: None declared, Yuko Kaneko Grant/ research support from: Abbvie, Eisai, Speakers bureau: AbbVie, Astellas, Ayumi, Bristol-Myers Squibb, Chugai, Eisai, Eli Lilly, Jansen, Kissei, Pfizer, Sanofi, Takeda, Tanabe-Mitsubishi, UCB, Jun Kikuchi: None declared, Tsutomu Takeuchi Grant/research support from: Astellas Pharma Inc, Chugai Pharmaceutical Co, Ltd., Daiichi Sankyo Co., Ltd., Takeda Pharmaceutical Co., Ltd., AbbVie GK, Asahikasei Pharma Corp., Mitsubishi Tanabe Pharma Co., Pfizer Japan Inc., Eisai Co., Ltd., AYUMI Pharmaceutical Corporation, Nipponkayaku Co. Ltd., Novartis Pharma K. K., Grant/research support from: AbbVie, Asahi Kasei, Astellas, AstraZeneca, AYUMI, Bristol-Myers Squibb, Chugai, Daiichi Sankyo, Eisai, Eli Lilly Japan, Janssen, Mitsubishi Tanabe, Nippon Kayaku, Novartis, Pfizer Japan Inc, Taiho, Taisho Toyama, Takeda, Teijin, Grant/research support from: Astellas Pharma Inc., Bristol Myers Squibb, Chugai Pharmaceutical Co., Ltd., Mitsubishi Tanabe Pharma Co., Pfizer Japan Inc., Santen Pharmaceutical Co., Ltd., Takeda Pharmaceutical Co., Ltd., Teijin Pharma Ltd., AbbVie GK, Asahi Kasei Pharma Corp., Taisho Toyama Pharmaceutical Co., Ltd., SymBio Pharmaceuticals Ltd., Janssen Pharmaceutical K.K., Celltrion Inc., Nipponkayaku Co. Ltd., and UCB Japan, Consultant for: Astra Zeneca K.K., Eli Lilly Japan K.K., Novartis Pharma K.K., Mitsubishi Tanabe Pharma Co., Abbivie GK, Nipponkayaku Co.Ltd, Janssen Pharmaceutical K.K., Astellas Pharma Inc., Taiho Pharmaceutical Co. Ltd., Chugai Pharmaceutical Co. Ltd., Taisho Toyama Pharmaceutical Co. Ltd., GlaxoSmithKline K.K., UCB Japan Co. Ltd., Consultant for: AbbVie, Asahi Kasei, Astellas, AstraZeneca, AYUMI, Bristol-Myers Squibb, Chugai, Daiichi Sankyo, Eisai, Eli Lilly Japan, Janssen, Mitsubishi Tanabe, Nippon Kayaku, Novartis, Pfizer Japan Inc, Taiho, Taisho Toyama, Takeda, Teijin, Consultant for: Astra Zeneca K.K., Eli Lilly Japan K.K., Novartis Pharma K.K., Mitsubishi Tanabe Pharma Co., Asahi Kasei Medical K.K., AbbVie GK, Daiichi Sankyo Co., Ltd., Bristol Myers Squibb, and Nipponkayaku Co. Ltd., Speakers bureau: Astellas Pharma Inc., Bristol Myers Squibb, Chugai Pharmaceutical Co., Ltd., Mitsubishi Tanabe Pharma Co., Pfizer Japan Inc., Santen Pharmaceutical Co., Ltd., Takeda Pharmaceutical Co., Ltd., Teijin Pharma Ltd., AbbVie GK, Asahi Kasei Pharma Corp., Taisho Toyama Pharmaceutical Co., Ltd., SymBio Pharmaceuticals Ltd., Janssen Pharmaceutical K.K., Celltrion Inc., Nipponkayaku Co. Ltd., and UCB Japan, Speakers bureau: AbbVie, Asahi Kasei, Astellas, AstraZeneca, AYUMI, Bristol-Myers Squibb, Chugai, Daiichi Sankyo, Eisai, Eli Lilly Japan, Janssen, Mitsubishi Tanabe, Nippon Kayaku, Novartis, Pfizer Japan Inc, Taiho, Taisho Toyama, Takeda, Teijin, Speakers bureau:
AbbVie GK., Bristol-Myers K.K., Chugai Pharmaceutical Co. Ltd., Mitsubishi Tanabe Pharma Co., Pfizer Japan Inc., Astellas Pharma Inc, Diaichi Sankyo Co. Ltd., Eisai Co. Ltd., Sanofi K.K., Teijin Pharma Ltd., Takeda Pharmaceutical Co. Ltd., Novartis Pharma K.K.

DOI: 10.1136/annrheumdis-2019-eular.3911

\section{SAT0149 EVALUATION OF A PROSPECTIVE COHORT EVENT MONITORING MODEL FOR PATIENT-REPORTED ADVERSE DRUG REACTIONSATTRIBUTED TO BIOLOGICAL DMARDS: VALIDITY OF THE PATIENT- REPORTED INFORMATION AND REPRESENTATIVENESS OF THE PARTICIPANTS}

Leanne Kosse $^{1}$, Naomi Jessurun ${ }^{1}$, Renske Hebing ${ }^{2}$, Victor Huiskes ${ }^{3}$, Karin Spijkers ${ }^{3}$, Michael Nurmohamed ${ }^{2,4} .{ }^{1}$ Netherlands Pharmacovigilance Centre Lareb, 's-Hertogenbosch, Netherlands; ${ }^{2}$ Amsterdam Rheumatology and Immunology Center, location Reade, Amsterdam, Netherlands; ${ }^{3}$ Sint Maartenskliniek, Ubbergen, Netherlands; ${ }^{4}$ Amsterdam Rheumatology and Immunology Center, location VU University Medical Center, Amsterdam, Netherlands

Background: To gain knowledge on the prevalence, course and treatment of adverse drug reactions (ADRs) attributed to biological DMARDs (bDMARDs) and the experienced impact of ADRs on patients, an ADRfocused online questionnaire system was developed by Netherlands Pharmacovigilance Centre Lareb (Dutch Biologic Monitor). 898 consecutive patients of eight centers who used a bDMARD indicated for an inflammatory rheumatic disease were followed between 1 January 2017 and 31 December 2018.

Objectives: Validation of the quality of the patient-reported information in the Dutch Biologic Monitor and evaluation of the representativeness of the participants in relation to the source populations.

Methods: Patients of 18 years and older who used a bDMARD indicated for an inflammatory rheumatic disease were included by the participating hospitals. The patient-reported medical information (bDMARD, indication and concomitant DMARDs) of 479 patients with a rheumatic disease (Reade, Amsterdam: $N=174$; Sint Maartenskliniek, Nijmegen: $N=305$ ) was verified by comparing the patient-reported parameters to the patient's electronic health record using percentage agreement and/or Cohen's kappa. Representativeness was tested in 550 patients with an inflammatory rheumatic disease (Reade, Amsterdam: $N=192$; Sint Maartenskliniek, Nijmegen: $N=358$ ) by comparing their grouped age, grouped gender and prescribed bDMARD to the source populations of the respective hospitals using Mann-Whitney $U$ test, Chi-Square Goodness-of-Fit and Fisher's exact test with Monte Carlo simulation.

Results: $95.8 \%$ of the tested rheumatic disease patients correctly reported their bDMARD (active substance and brand name). Furthermore, agreement between patients and the electronic health record was strong for the reported indications $(90.4 \%$ agreement, $\kappa=0.832)$ and moderate for the concomitant therapy $(79.7 \%$ agreement; $\kappa=0.725)$. The subpopulations were representative for their source populations based on grouped gender $(38.4 \%$ vs. $38.8 \%$ male, $\chi 2(d f=1, \quad N=550)=0.038 ; p>0.05)$ and bDMARD use (both $p>0.05$ ). Grouped median age was not representative (58.0 vs. 56.0 years; $U=962872 ; p=0.04)$, since the male participants were olde (58.5 vs. 55 years; $p=0.001$ ).

Conclusion: So far, the Dutch Biologic Monitor seems to be a valid too to obtain knowledge on ADRs attributed to bDMARDs, since the reported medical information corresponded to the patients' electronic health records and the participants generally represented their source populations regarding grouped gender and prescribed bDMARD.

Disclosure of Interests: Leanne Kosse: None declared, Naomi Jessurun None declared, Renske Hebing: None declared, Victor Huiskes: None declared, Karin Spijkers: None declared, Michael Nurmohamed Grant/ research support from: AbbVie, Bristol-Myers Squibb, Celgene, Eli Lilly, Janssen, Menarini, MSD, Mundipharma, Pfizer, Roche, Sanofi and UCB Consultant for: AbbVie, Bristol-Myers Squibb, Celgene, Eli Lilly, Janssen, Menarini, MSD, Mundipharma, Pfizer, Roche, Sanofi and UCB, Speakers bureau: AbbVie, Bristol-Myers Squibb, Celgene, Eli Lilly, Janssen, Menarini, MSD, Mundipharma, Pfizer, Roche, Sanofi and UCB DOI: 10.1136/annrheumdis-2019-eular.5324 